\title{
Imagens que carregamos às costas
} Albert Elduque $^{1}$

Congresso "Liberation Struggles, The 'Falling of the Empire' and the Birth (through Images) of African Nations", Centre for Film Aesthetics and Cultures, University of Reading, Reading, e Camões Centre for Portuguese Language and Culture, King's College, Londres, 27 e 28 de janeiro de 2016.

Duas fotografias coladas, uma por detrás da outra, formando um objeto de duas faces. De um lado, uma criancinha na praia. No outro, um guineense assassinado durante a guerra de libertação da excolónia portuguesa. A primeira é uma fotografia de família de Daniel Barroca, artista português. A segunda, uma imagem que encontrou escondida no álbum do seu pai, soldado do regime português durante a guerra da independência daquele país africano. Um fio preso ao teto, movimentando-se sem parar, faz a dupla imagem girar, continuamente, como um taumatrópio: uma foto persegue a outra, tentando sobrepor-se a ela mas assumindo uma separação insuperável entre ambas.

Este é o dispositivo subjacente a Circular Body, uma instalação de Daniel Barroca exposta na desaparecida galeria de arte De La Charge, em Bruxelas, em 2015. O título sugere um vínculo físico entre duas imagens inextricavelmente ligadas, uma nas costas da outra, morando juntas, mas sem poder conversar cara a cara. Com Circular Body, Barroca cria uma montagem simples para exprimir a sua problemática relação com o passado colonial português, que seu pai defendeu. Se o olhar do menino de Alemanha, Ano Zero (Germania anno zero, Roberto Rossellini, 1947) era esmagado quando encontrava uma realidade em ruínas, Barroca, o menino e o artista, tenta compreender um passado sangrento, inicialmente invisível para ele.

Nos passados 27 e 28 de janeiro, o Centre for Film Aesthetics and Cultures da University of Reading e o Instituto Camões do King's College de Londres acolheram o congresso internacional Liberation Struggles, The 'Falling of the Empire' and the Birth (through Images) of African Nations. O seu propósito era abordar o processo de descolonização dos territórios portugueses em África e pensar como foi refletido ou produzido por novas imagens, realizadas tanto pelos cineastas portugueses como pelos dos novos países africanos, além de outros vindos de outros lugares, como o Brasil. O evento reuniu cerca de trinta pesquisadores (trabalhando em Portugal, no

\footnotetext{
${ }^{1}$ University of Reading, Department of Film, Theatre and Television, Minghella Studios, Shinfield Road, RG6 6BT Reading, Reino Unido.
} 
Reino Unido, em França, na Alemanha, na Roménia e no Brasil, mas maioritariamente portugueses) e foi organizado por Maria do Carmo Piçarra, dinamizadora da Aleph - Rede de Acção e Investigação Crítica da Imagem Colonial.

O evento integrou seis mesas de comunicações, cujas designações definem bem os conflitos visuais e históricos abordados: "(Des)construindo a projeção das nações africanas através do cinema", "Memória e olhares sobre o 'arquivo colonial", "O nascimento [através das imagens] das nações africanas”, "Representações fílmicas (pós)coloniais", "Propaganda e lutas de libertação: olhares estrangeiros” e “(Des)construção do 'arquivo colonial': práticas artísticas”. Estas designações não compõem simplesmente uma enumeração de temas e mesas de discussão, mas uma lista que, ela mesma, é um texto aberto e problemático. Encontram-se aqui múltiplas dúvidas: o inciso "[através das imagens]", o jogo com os parênteses no verbo "(des)construir" e na palavra "(pós-)colonial" ou as aspas para mencionar o "arquivo colonial". Estes jogos de palavras dão voz a dúvidas sobre a História e sua representação, sobre temporalidades e sobre ponto de vista, que estiveram no cerne do congresso. Um congresso vivo, sem poeira, completado também com apresentações de trabalhos artísticos, arquivísticos, ou artísticos e arquivísticos ao mesmo tempo. Superavam-se, assim, os limites da academia, por vezes estreitos demais, para atingir também as esferas da conservação e da criação, com os olhos postos tanto no passado como no futuro, dando pulos e até invertendo estes dois conceitos.

A instalação de Daniel Barroca fornece-nos de uma metáfora para pensar nas liberation struggles (lutas de libertação) analisadas nas distintas comunicações. Na verdade, a relação problemática com o passado que a sua obra apresenta é também vivida pelos investigadores que estudam fotografia ou cinema, e por isso tratou-se, sobretudo, de lutas no território das imagens - quer por via de formas de representação novas que questionam as velhas, quer através da recuperação de memórias que tinham sido encerradas em antigos arquivos oficiais ou familiares. Relataram-se lutas vividas no campo da criação e na trincheira da pesquisa, talvez exorcismos de uma história portuguesa que pede para ser interrogada. Através das distintas contribuições tornou-se possível mapear algumas das formas que pode tomar essa contra-história, ou canais por onde pode circular por exemplo, Paulo Cunha falou das relações entre os cineclubes das colónias e aqueles da metrópole durante o período colonial; Maíra Zenun de Oliveira abordou o FESPACO, o festival de cinema mais antigo da África; enquanto Leandro Mendonça apresentou uma proposta metodológica para estudar as imagens produzidas nos países lusófonos. A estas visões somaram-se aproximações a partir de uma perspetiva teórica sobre a hibridização pós-colonial, como na apresentação de Pedro Andrade, ou da antropologia, como a comunicação de Catarina Laranjeiro sobre o vínculo entre a resis- 
tência anticolonial e os irãs (entidades espirituais) na Guiné-Bissau. Em todos os casos, desenharam-se trilhos alternativos a partir dos quais se pode questionar a História.

Um dos pontos altos do encontro foi a reflexão proposta sobre como a descolonização ganhou expressão em obras fílmicas produzidas tanto dentro como fora das colónias. Enquadram-se nesse caso vários filmes realizados no calor da hora, ou quase, como Angola: A Journey to War (Robert Young e Robert McCormick, 1961), abordado por Afonso Ramos; Vinte e cinco (José Celso e Celso Lucas, 1976), examinado por Ros Gray e Robert Stock; Mueda, Memória e Massacre (Ruy Guerra, 1979), analisado por Stock e Raquel Schefer, e Acto dos Feitos de Guiné (Fernando Matos Silva, 1980), um dos focos da comunicação de Maria-Benedita Basto. Por outro lado, Raquel Ribeiro e Iolanda Vasile analisaram as relações diplomáticas ou culturais entre os novos países africanos e outros estados da esfera socialista, como Cuba ou a Roménia, respetivamente. A partir de todas as apresentações surgiram múltiplas perguntas: como representar a História? Como criar novas formas de expressão para afirmação dos novos países, completando uma emancipação que também precisava de ser visual? Como distanciar-se das imagens oficiais veiculadas pelas propagandas nacionais? Estas são questões não resolvidas, e que também ressoaram com força nas comunicações focadas em filmes contemporâneos, nos quais a História toma forma de lenda, fantasma ou horror reprimido. Nuno Barradas Jorge falou de vários filmes de Pedro Costa, Lúcia Nagib de A costa dos murmúrios (Margarida Cardoso, 2004) e Tabu (Miguel Gomes, 2012), Katy Stewart de O grande Kilapy (Zézé Gamboa, 2012), e Rosa Cabecinhas focou-se em Ilha da Cova da Moura (Rui Simões, 2010) e Cavalo dinheiro (Pedro Costa, 2014), filme este que foi projetado no fim do primeiro dia do congresso.

O grande protagonista das discussões foi, porém, o arquivo. Acervos oficiais e familiares, propagandísticos e militantes, em Portugal e nas suas ex-colónias, conhecidos e a redescobrir, mas sempre operando nesse corpo circular da memória que Daniel Barroca propõe na sua instalação. José Manuel da Costa, diretor da Cinemateca Portuguesa, explicou como está organizado o arquivo colonial da instituição, enquanto o pesquisador Lee Grieveson, da University College London, apresentou os resultados do projeto Colonial Film: Moving Images of the British Empire, de que foi um dos coordenadores, e que no seu site (www.colonialfilm.org.uk) apresenta informação sobre mais de 6000 obras filmadas nas colónias do Império Britânico, disponibilizando em linha mais de 150 desses filmes.

Infelizmente não existe, no caso do antigo império português, uma plataforma igual, mas sim numerosos trabalhos que incorporam o arquivo de forma crítica, como aqueles de Daniel Barroca ou Manuel Santos Maia. Trata-se de aproximações ao arquivo que são 
menos académicas e mais pessoais, localizáveis na Internet ou em salas de exibição, onde formam um panorama não sistematizado. As comunicações apresentadas deram algumas pistas para mapear essa produção efervescente sobre a memória: Ana Balona de Oliveira falou sobre trabalhos de Ângela Ferreira, Kiluanji Kia Henda, Délio Jasse e Daniel Barroca; Teresa Castro abordou o conceito do artista como pesquisador comentando o trabalho de vários artistas, como Santos Maia ou Andreia Sobreira, e Ricardo Mendonça analisou as intervenções artísticas sobre os monumentos memoriais nas antigas colónias.

O congresso dedicou espaços privilegiados à apresentação de obras artísticas sobre o arquivo. No primeiro dia, Daniel Barroca, em diálogo com Teresa Castro, comentou alguns dos seus trabalhos, entre eles Circular Body. Desenhou-se assim um percurso triangular entre autobiografia, História e arte, onde qualquer destes três pontos pode atingir o outro por meio do terceiro, permitindo múltiplas combinações. No segundo dia, a artista Filipa César apresentou o projeto coletivo Luta ca caba inda, que, no âmbito de uma pesquisa sobre as origens da produção cinematográfica no país, recuperou filmes que estavam em processo de degradação no Instituto Nacional do Cinema e Audiovisual da Guiné-Bissau (INCA). Relatando uma história apaixonante (com referências a Chris Marker, que ela entrevistou, incluídas), César defendeu que o arquivo nunca é irrelevante, ele é sempre poderoso, e preferiu não falar em "restauro" por considerar que o processo não é uma coisa do passado mas do presente.

A atualidade do arquivo afirma-se, assim, por duas vias. Em primeiro lugar, pela sua inevitável influência no nosso agora: não é possível compreender o nosso regime visual sem conhecer as suas origens imediatas. O passado, pois, não é remoto nem superado: fala de hoje. Em segundo lugar, é importante pensar que não só o passado deixa rastos no presente, mas também o presente deixa rastos no passado. O arquivo é inseparável do momento da sua consulta e esse momento acontece hoje: é hoje que encontramos os motivos do uso desse arquivo (o surgir de uma geração de artistas e pesquisadores que, por situação histórica, empreende esse processo de memória), e é com olhos de hoje que esse arquivo é lido, interrogado e até moldado. "Restauro", pois, não é com certeza a melhor palavra; também não, claro, mumificação nem taxidermia; restituição, diálogo, encarnação, figuração... parecem melhores.

Assim chegamos, mais uma vez, a Circular Body, e pensamos de novo que as imagens fixadas ou filmadas décadas atrás, e que carregamos às costas, afirmam constantemente a sua presença, contrariando aqueles que acham que são coisas do passado. Atender a essa afirmação, pensar em como se produz esse virar entre o olhar e a História, e escrever a partir dessa corda bamba entre imagem e imagem, foi a luta levada a cabo nestas liberation struggles/lutas de libertação. Estas são lutas que todos precisamos empreender, 
379 | ALBERT ELDUQUE

olhando com suspeita para as nossas memórias pessoais, coletivas e cinematográficas. 